\title{
Smoking Trajectories, Health, and Mortality across the Adult Lifespan
}

\author{
Zachary A.K. Frosch ${ }^{\mathrm{a}}$, Lisa C. Dierker ${ }^{\mathrm{a}}{ }^{*}$, Jennifer S. Rose ${ }^{\mathrm{a}}$, and Robert J. Waldinger ${ }^{\mathrm{b}}$ \\ a Wesleyan University Department of Psychology, 207 High Street, Middletown, CT 06459, United States \\ b Harvard Medical School and Brigham and Women's Hospital, 1249 Boylston Street - 3rd floor, Boston, \\ MA 02215, United States
}

\begin{abstract}
This study extends research on the association between smoking behavior and chronic disease by following a cohort from the time of initiation of regular smoking patterns into old age and by examining the association of lifetime smoking trajectories with chronic disease and mortality. Participants consisted of 232 males selected from the Harvard classes of 1942-1944 and followed biennially through 2003. Five distinct smoking trajectories were identified based on the age at which participants quit daily smoking. Participants following smoking trajectories with later cessation had a higher likelihood of developing lung disease and lived shorter lives than those who quit smoking at an earlier age. This study confirms that the earlier a smoker quits, the greater the health benefits, and that these benefits are observed even decades after smoking cessation. Additionally, by showing different survival rates between trajectory groups 25 and 40 years after quitting, the results run counter to previous work that has found no difference in mortality between smokers and non-smokers 15 years after cessation.
\end{abstract}

\section{Keywords}

Smoking (Tobacco); Mortality; Smoking Cessation

\section{Introduction}

Smoking, the single most preventable cause of premature death in the United States, results in 440000 deaths annually, (MMWR, 2003). Retrospective reports have indicated smoking is associated with specific negative health outcomes, including several types of cancer, as well as, cardiovascular and respiratory diseases (USDHHS, 2004). Prospective work has confirmed many of these associations (Engeland, Haldorsen, Anderson, \& Tretli, 1996; Freund, 1993; Giovannucci et al., 1994; Godtfredsen, Prescott, \& Osler, 2005; Hirdes, Brown, Vigoda, Forbes, \& Crawford, 1987; Howard et al., 1998; Lam et al., 1997; Nusselder, Looman, Mheen, Mheen, \& Mackenbach, 2000; Ostbye \& Taylor, 2004; Ostbye, Taylor, \& Jung, 2002; Prescott, Hippe, Schnohr, Hein, \& Vestbo, 1998; Prescott et al., 1998; Simons, Simons, McCallum, \& Friedlander, 2005; Wannamethee, Shaper, \& Perry, 2001; Weir, 1970; Yuan et al., 1996) and

*Corresponding Author: Department of Psychology, Wesleyan University 207 High Street, Middletown, CT 06459, United States. Email address: E-mail: 1dierker@wesleyan.edu; tel: 860 685-2137; fax: 860-685-2761.

Publisher's Disclaimer: This is a PDF file of an unedited manuscript that has been accepted for publication. As a service to our customers we are providing this early version of the manuscript. The manuscript will undergo copyediting, typesetting, and review of the resulting proof before it is published in its final citable form. Please note that during the production process errors may be discovered which could affect the content, and all legal disclaimers that apply to the journal pertain. 
has demonstrated a temporal ordering suggesting the likelihood of a causal relationship between smoking and these disease outcomes.

Most often, prospective studies are conducted over short periods, with few following study participants for longer than a decade (Giovannucci et al., 1994; Howard et al., 1998; Ostbye, Taylor, \& Jung, 2002; Weir, 1970; Yuan et al., 1996), and many measuring smoking behavior during only one assessment (Engeland, Haldorsen, Anderson, \& Tretli, 1996; Enstrom, 1999; Hirdes, Brown, Vigoda, Forbes, \& Crawford, 1987; Lam et al., 1997; Rogot \& Murray, 1989). Among studies of United States populations with the longest periods of repeated longitudinal smoking assessment, including the Framingham Study (Freund, Belanger, D'Agostino, \& Kannel, 1993; Freund, 1992; Gordon, 1975) and the First Cancer Prevention Study (CPS-I) (Knoke, Shanks, Vaugh, Thun, \& Burns, 2004; Thun, Day-Lally, Calle, Flanders, \& Heath Jr, 1995; Thun \& Heath Jr, 1997), baseline smoking behavior is captured at entry through reports by adults who have long passed the age of risk for smoking initiation and established use. Because most smokers quit and relapse repeatedly before abstaining permanently, short term, compressed, and averaged smoking measurements are necessarily simplifications of the quitting process (USDHHS, 1990), and fail to maximally characterize changes in smoking behavior across the lifespan.

One analytic approach that better captures smoking behavior is latent class growth analysis (LCGA), which seeks to identify population subgroups that follow distinct behavioral trajectories (Muthén \& Muthén, 2000; Nagin, 1999). While prospective work using such analysis has defined trajectories of smoking behavior within adolescence and across early adulthood (Chassin, Presson, Pitts, \& Sherman, 2000), trajectories across the lifespan have not been empirically characterized, nor has the association between smoking trajectories and disease been investigated. The present study aims to extend previous research in the following ways: (1) by following a cohort from the time of initiation of regular smoking patterns (i.e., age 21) into old age (i.e., age 82), when chronic illness is most likely to impact health and longevity; and (2) by evaluating the association between an individual's tendency to follow a particular smoking trajectory and chronic diseases and mortality.

\section{Methods}

\subsection{Participants}

The present analysis utilized a male sample selected from the Harvard classes of 1942-1944 (Vaillant, 1979). The 268 participants had a mean birth year of 1921 ( $S D=2$ years) and were selected as sophomores from 1938-1942 (Vaillant, 1996). Participants were followed by annual or biennial questionnaires, which included questions regarding smoking behavior, from age 21 (Vaillant, 2003) through 2003. Thirty-six participants missing tobacco data on 17 or more of the 22 assessments were excluded (95th percentile or higher for amount of missing data).

\subsection{Measurement}

Questionnaires included items inquiring whether the individual smoked cigarettes, pipes, or cigars and, if so, how many per day. Participants were considered daily smokers in a year if they indicated smoking any type of tobacco on a daily basis. Non-smokers included participants who indicated no use of any type of tobacco at that assessment and those indicating that their use of tobacco was less than daily. Quitting daily smoking was defined as reporting no daily use of tobacco following one or more assessments where daily smoking was reported.

Physical health was coded by an internist who reviewed each participant's health records, obtained from their physicians every five years. Disease categories included: cancer (cancer, 
CA, carcinoma, adenoma, malignant lymphoma, melanoma, chronic lymphocytic leukemia, basal cell epithelioma, glioma); heart disease (myocardial infarction, coronary artery disease, congestive heart failure, cardiomyopathy, graft or angioplasty of coronary artery, angina, ischemia); vascular disease (peripheral vascular disease, aortic aneurysm, angioplasty of any peripheral vessel, deep vein thrombosis, carotid or aortic stenosis, varicosities, carotid occlusion, carotid artery surgery, aortic insufficiency, aortic sclerosis, carotid endarterectomy, bypass of a peripheral vessel, lateral ischemia, vascular dementia, vessel stent, venous stasis, pulmonary embolism); hyperlipidemia: (hypercholesterolemia, high lipids, low HDL, high LDL, dyslipidemia, high cholesterol, hyperlipidemia); diabetes (diabetes mellitus, glucose intolerance, glucose tolerance, high glucose); cerebrovascular disease (cerebrovascular accident, transient ischemic attack, infarct, sub-arachnoid hemorrhage, brain hemorrhage); hypertension (hypertension, high blood pressure, on antihypertensives); and lung disease (chronic obstructive pulmonary disease, hyperinflated lungs, pneumonia, tuberculosis, pulmonary edema, emphysema, lung resection, lung abscess). If any of these diagnoses were listed as a cause of death on a participant's death certificate, the condition was coded as present.

\subsection{Data Analysis}

Trajectories were identified using LCGA (Muthén \& Muthén, 2000; Nagin, 1999). Linear trajectory models specifying two through six classes were tested. Several recommended criteria were used to determine which model to retain (Nagin, 1999, 2005). Participants were then assigned to their trajectory group based on posterior probabilities for each class. Chi-square analyses were conducted to compare different trajectory groups on a number of discrete descriptive smoking characteristics and disease outcome variables. Where a significant result was found, post-hoc paired comparisons were conducted. Finally, a discrete time survival LCGA was conducted to evaluate whether progression in the probability of mortality (mortality hazard rate) varied across trajectory classes.

\section{Results}

Based on model fit statistics and parsimony, a five class trajectory model was chosen. Although the adjusted Lo-Mendell-Rubin test suggested retaining a six-class model, there was no improvement in the BIC for the six-class model, and the average posterior probabilities dropped below 0.70 for two of the classes, suggesting a loss in classification quality. While the BIC was slightly higher for the four-class model than for the five-class model, this difference was minimal and represented virtually no improvement in model fit. Additionally, the Lo-MendellRuben test for the five-class model was significant at $\mathrm{p}<.05$, providing additional evidence for retaining the five-class model. Finally, the five classes differed significantly in their smoking behavior, providing substantive evidence in support of a five-class solution.

Average latent class trajectories showing the mean estimated probability of smoking at each time point for the five distinct groups of smokers are shown in Figure 1. A small number of "lifetime users" $(\mathrm{n}=11$; average posterior probability $=0.94)$ maintained tobacco use across their lifespan. "Late quitters" ( $n=48$; average posterior probability $=0.71)$ smoked until a median age of 69 . Tobacco use for "middle quitters" ( $\mathrm{n}=69$; average posterior probability = $0.85)$ declined steadily and they quit at a median age of 56. "Early quitters" ( $\mathrm{n}=26$; average posterior probability $=0.70$ ) ceased daily smoking sooner than other groups (i.e. median age of 40$)$. For "low users" $(n=78$; average posterior probability $=0.95)$, tobacco use remained minimal across measurements.

Table 1 summarizes disease outcomes for the different trajectory classes. Differences between groups were observed only for lung disease. Post-hoc paired comparisons showed that late quitters had a higher prevalence of lung disease than low users and early quitters. Further, 
middle quitters had a higher rate of lung disease than early quitters. No differences in rates of the remaining disease categories were found among the trajectory classes.

Results of the discrete time survival latent class growth analysis indicated that, compared to low users and early quitters, middle and late quitters were less likely to survive to an advanced age. There were no significant differences in hazard rates between low users and early quitters and between middle and late quitters. Estimated survival curves (Figure 2) suggested that low users had a higher probability of survival by age $81-85$, whereas late quitters had the lowest survival probability by age $81-85$. Survival curves were similar for early and middle quitters, but by age $65-69$, middle quitters had a significantly lower survival probability. Though lifetime users had an unexpectedly high survival probability in comparison to other groups, the fact that this class contained only 11 participants increases the likelihood that this result is not representative of this group of smokers.

\section{Discussion}

This study extends research on associations between smoking behavior and chronic disease by following a male cohort from initiation of regular smoking behavior into old age. Because smoking was measured at multiple points over the participants' lifetime, this study presented a unique opportunity to examine the natural history of smoking behavior. Three major findings emerged. First, the sample contained five distinct smoking trajectories based on the age at which participants quit daily smoking. Second, those participants following smoking trajectories with later cessation had a higher likelihood of developing lung disease than those who quit smoking at an earlier age. Finally, participants following trajectories with later cessation lived shorter lives.

While previous studies have examined smoking trajectories from adolescence into early adulthood (Chassin, Presson, Pitts, \& Sherman, 2000), to our knowledge, this is the first to investigate trajectories of smoking across the adult lifespan. Results suggest that low users were at reduced risk for lung diseases compared to late quitters and had a lower probability of death compared to both middle and late quitters. Early quitters were similar to low users in disease and mortality, had a lower lifetime prevalence of lung disease than middle and late quitters, and lived longer than middle and late quitters. Late quitters lived significantly shorter lives than early quitters and low users. Comparing the survival curves of middle and late quitters shows that, by age 81 to 85 , late quitters were more likely to have died than middle quitters. Though this difference was not significant in the present sample, it is possible that with a larger sample a significant difference would be observed.

These findings confirm previous research documenting the health benefits of smoking cessation. Large studies show that after 15 years of abstinence, smokers are not more likely than never-smokers to be in poor health (Ostbye, Taylor, \& Jung, 2002) and that their risk of mortality returns to nearly the level of nonsmokers (USDHHS, 1990). The present study confirms the benefits of quitting and demonstrates a protective effect of early smoking cessation. However, the results also run counter to previous work by demonstrating differences in mortality between groups even after 15 years of smoking abstinence. Though the survival curve analysis showed that early quitters and low users had similar longevity, early quitters had a significantly higher survival probability than middle quitters at age $81-85$, over 25 and 40 years after the average quitting age for these groups. This suggests that after a long period of abstinence the risk of mortality in smokers may return to that of non-smokers, but that the earlier a smoker quits, the greater the health benefits.

One limitation of this study is small sample size. It is possible that a larger sample may have provided the power necessary to replicate the previously demonstrated associations between 
smoking and other chronic diseases examined in this study. Other limitations derive from the homogeneity of the sample and have been outlined previously (Vaillant, 1979, 1998). The sample is educationally and racially homogeneous and was pre-selected for good health. However, the selection of these men for their health minimizes the possibility of a pre-existing condition, thus maximizing the probability that the conditions examined were developed during the observation period. Moreover, while the homogeneity of the sample limits the generalizability of the results, it eliminates the need to control for factors such as education, socio-economic class, race, and gender, which would dramatically increase sample size requirements.

\section{Acknowledgments}

The Study of Adult Development has been supported for the last 20 years by a grant from the National Institute of Mental Health: R01 MH042248. Data analyses and interpretation, manuscript preparation, review and approval were supported by grants DA15454 and DA024260 from the National Institute of Drug Abuse (Dierker), and an Investigator Award from the Patrick \& Catherine Weldon Donaghue Medical Research Foundation (Dierker), and Center Grant (DA010075) awarded to the Methodology Center, Penn State University. The authors report no conflicts of interest in the reporting of these findings.

\section{References}

Chassin L, Presson C, Pitts S, Sherman S. The natural history of cigarette smoking from adolescence to adulthood in a Midwestern common sample: Multiple trajectories and their psychosocial correlates. Health Psychology 2000;19:223-231. [PubMed: 10868766]

Engeland A, Haldorsen T, Anderson A, Tretli S. The Impact of Smoking Habits on Lung Cancer Risk: 28 Years' Observation of 26,000 Norwegian Men and Women. Cancer Causes \& Control 1996;7(3): 366-376. [PubMed: 8734831]

Enstrom JE. Smoking Cessation and Mortality Trends Among Two United States Populations. Journal of Clinical Epidemiology 1999;52(9):813-825. [PubMed: 10529023]

Freund K, Belanger A, D' Agostino R, Kannel W. The health risks of smoking. The Framingham Study: 34 years of follow-up. Annals of Epidemiology 1993;3(4):417-424. [PubMed: 8275219]

Freund KM. Predictors of smoking cessation: the Framingham Study. American Journal of Epidemiology 1992;135(9):957-964. [PubMed: 1595694]

Freund KM, Belanger AJ, D'Agostino RB, Kannel WB. The health risks of smoking. The Framingham Study: 34 years of follow-up. Annals of Epidemiology 1993;3(4):417-424. [PubMed: 8275219]

Giovannucci E, Rimm EB, Stampfer MJ, Colditz GA, Ascherio A, Kearney J, et al. A Prospective Study of Cigarette Smoking and Risk of Colorectal Adenoma and Colorectal Cancer in U.S. Men. Journal of the National Cancer Institute 1994;86:183-191. [PubMed: 8283490]

Godtfredsen NS, Prescott E, Osler M. Effect of Smoking Reduction on Lung Cancer Risk. Journal of the American Medical Association 2005;294(12):1505-1510. [PubMed: 16189363]

Gordon TK, Williamm B, Dawber T, McGee D. Changes associated with quitting cigarette smoking: The Framingham Study. The American Heart Journal 1975;90(3):322-328.

Hirdes JP, Brown KS, Vigoda DS, Forbes WF, Crawford L. Health Effects of Cigarette Smoking: Data from the Ontario Longitudinal Study on Aging. Canadian Journal of Public Health 1987;78(1):1317.

Howard G, Wagenknecht LE, Burke GL, Diez-Roux A, Evans GW, McGovern P, et al. Cigarette Smoking and Progression of Atherosclerosis. Journal of the American Medical Association 1998;279(2):119124. [PubMed: 9440661]

Knoke JD, Shanks TG, Vaugh JW, Thun MJ, Burns DM. Lung Cancer Mortality Is Related to Age in Addition to Duration and Intensity of Cigarette Smoking: An Analysis of CPS-1 Data. Cancer Epidemiology, Biomarkers \& Prevention 2004;13(6):949-957.

Lam TH, He Y, Li LS, Li LS, He FS, Liang BQ. Mortality Attributable to Cigarette Smoking in China. Journal of the American Medical Association 1997;278(18):1505-1508. [PubMed: 9363970]

MMWR. Cigarette Smoking-Attributable Morbidity --- United States, 2000. CDC Morbidity and Mortality Weekly Report 2003;52(35):842-844. 
Muthén B, Muthén LK. Integrating person-centered and variable-centered analyses: growth mixture modeling with latent trajectory classes. Alcoholism: Clinical and Experimental Research 2000;24 (6):882-891.

Nagin D. Analyzing developmental trajectories: a semi-parametric group-based approach. Psychological Methods 1999;4:139-157.

Nagin, D. Group-Based Modeling of Development. Cambridge, MA: Harvard University Press; 2005.

Nusselder WJ, Looman CWN, Marang-van de Mheen PJ, van de Mheen H, Mackenbach JP. Smoking and the compression of morbidity. Journal of Epidemiolgy and Community Health 2000;54:566574.

Ostbye T, Taylor DH. Smoking and Substance Abuse: The Effect of Smoking on Years of Health Life (YHL) Lost Among Middle-Aged and Older Americans. HSR: Health Services Research 2004;39 (3):531-552.

Ostbye T, Taylor DH, Jung SH. A Longitudinal Study of the Effects of Tobacco Smoking and Other Modifiable Risk Factors on Ill Health in Middle-Aged and Old Americans: Results from the Health and Retirement Study and Asset and Health Dynamics among the Oldest Old Survey. Preventative Medicine 2002;34:334-345.

Prescott E, Hippe M, Schnohr P, Hein HO, Vestbo J. Smoking and risk of myocardial infarction in women and men: longitudinal population study. BMJ (British Medical Journal) 1998;316:1043-1047.

Prescott E, Osler M, Hein HO, Borch-Johnsen K, Schnohr P, Vestbo J. Life expectancy in Danish women and men related to smoking habits: smoking may affect women more. Journal of Epidemiology Community Health 1998;52:131-132.

Rogot E, Murray JL. Smoking and Causes of Death Among U.S. Veterans: 16 Years of Observation. Public Health Reports 1989;95(3):213-222. [PubMed: 7384406]

Simons LA, Simons J, McCallum J, Friedlander Y. Impact of smoking, diabetes and hypertension on survival time in the elderly: the Dubbo Study. The Medical Journal of Australia 2005;182(5):219222. [PubMed: 15748131]

Thun M, Day-Lally C, Calle E, Flanders WD, Heath C Jr. Excess Mortality among Cigarette Smokers: Changes in a 20-Year Interval. American Journal of Public Health 1995;85(9):1223-1230. [PubMed: 7661229]

Thun MJ, Heath CW Jr. Changes in Mortality from Smoking in Two American Cancer Society Prospective Studies since 1959. Preventative Medicine 1997;26:422-426.

USDHHS. US Department of Health and Human Services: Public Health Service: Office on Smoking and Health. 1990. The Health Benefits of Smoking Cessation.

USDHHS. US Department of Health and Human Services, Centers for Disease Control and Prevention, National Center for Chronic Disease Prevention and Health Promotion, Office on Smoking and Health. 2004. The Health Consequences of Smoking: A Report of the Surgeon General.

Vaillant GE. Natural History of Male Psychological Health: Effects of Mental Health on Physical Health. New England Journal of Medicine 1979;301(23):1249-1254. [PubMed: 503127]

Vaillant GE. A Long-term Follow-up of Male Alcohol Abuse. Archives of General Psychiatry 1996;53:243-249. [PubMed: 8611061]

Vaillant GE. Natural History of Male Psychological Health, XIV: Relationship of Mood Disorder Vulnerability to Physical Health. American Journal of Psychiatry 1998;155(2):184-191. [PubMed: 9464196]

Vaillant GE. A 60-year follow-up of alcoholic men. Addiction 2003;98:1043-1051. [PubMed: 12873238]

Wannamethee SG, Shaper AG, Perry IJ. Smoking as a Modifiable Risk Factor for Type 2 Diabetes in Middle-Aged Men. Diabetes Care 2001;24(9):1590-1595. [PubMed: 11522704]

Weir JM, Dunn JE Jr. Smoking and mortality: a prospective study. Cancer 1970;25(1):105-112. [PubMed: 5410301]

Yuan JM, Ross RK, Wang XL, Gao YT, Henderson BE, Yu MC. Morbidity and Mortality in Relation to Cigarette Smoking in Shanghai, China: A Prospective Male Cohort Study. Journal of the American Medical Association 1996;275(21):1646-1650. [PubMed: 8637137] 


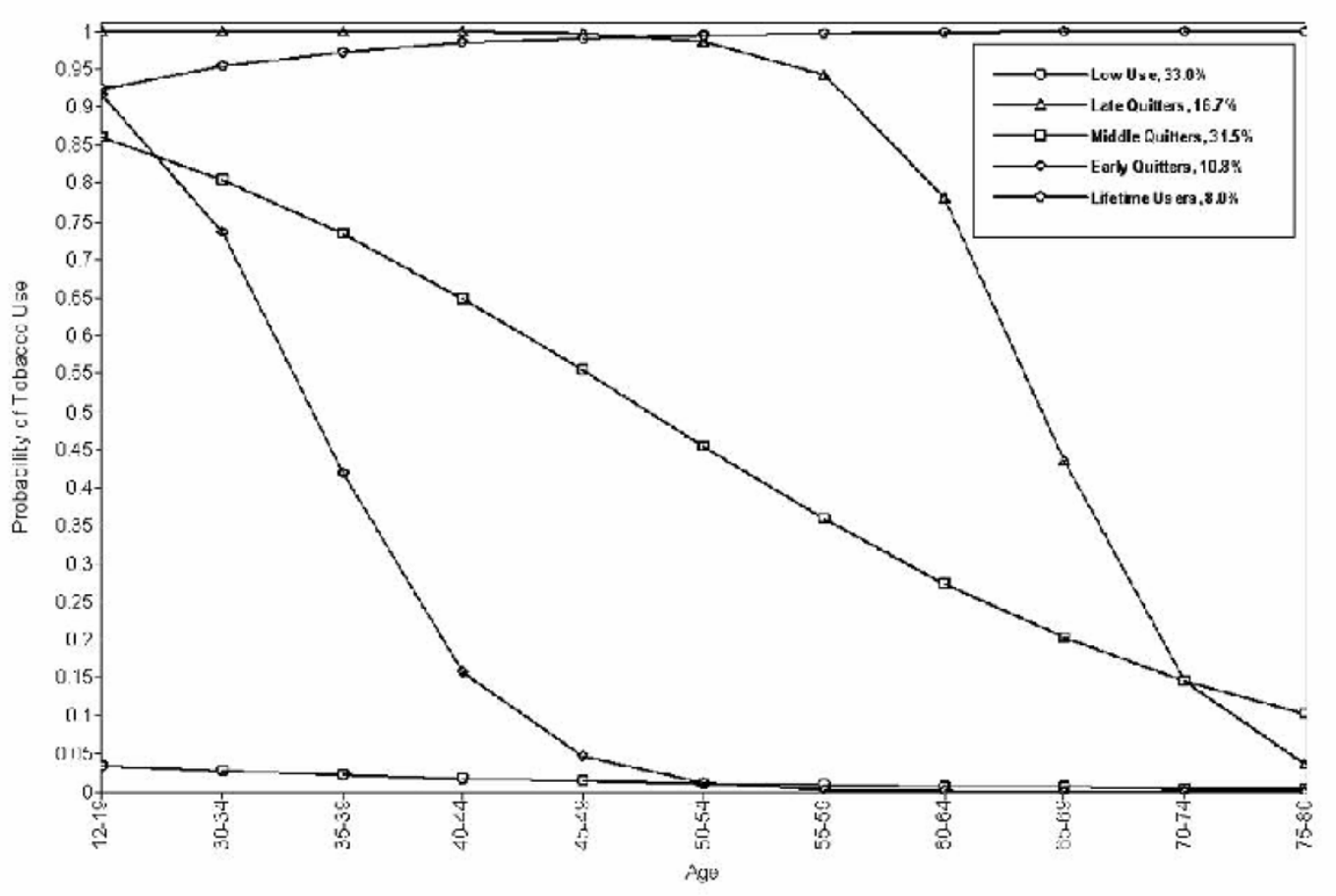

Figure 1. 


\section{Latert Trajectory Class Survival Curves}

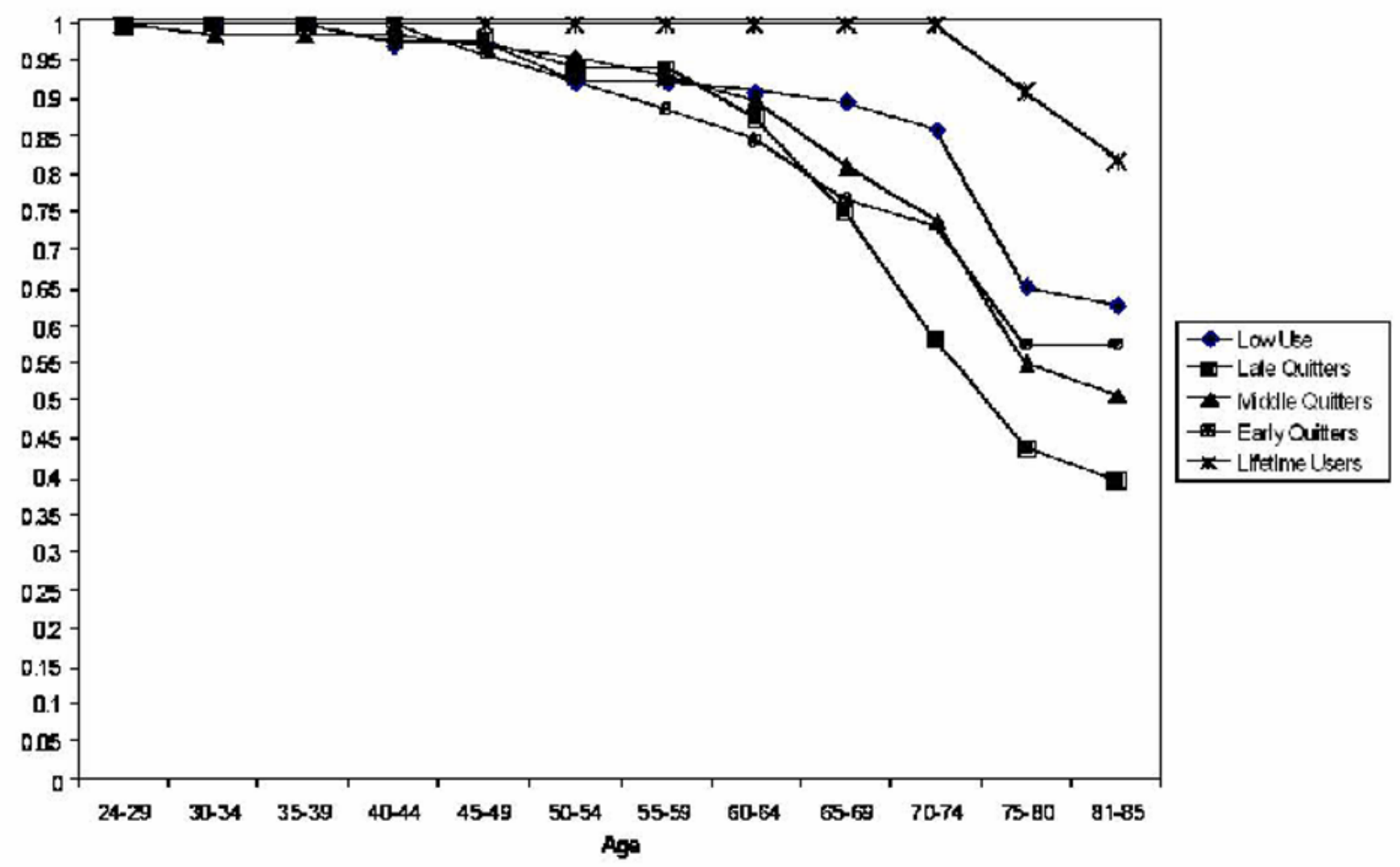

Figure 2. 


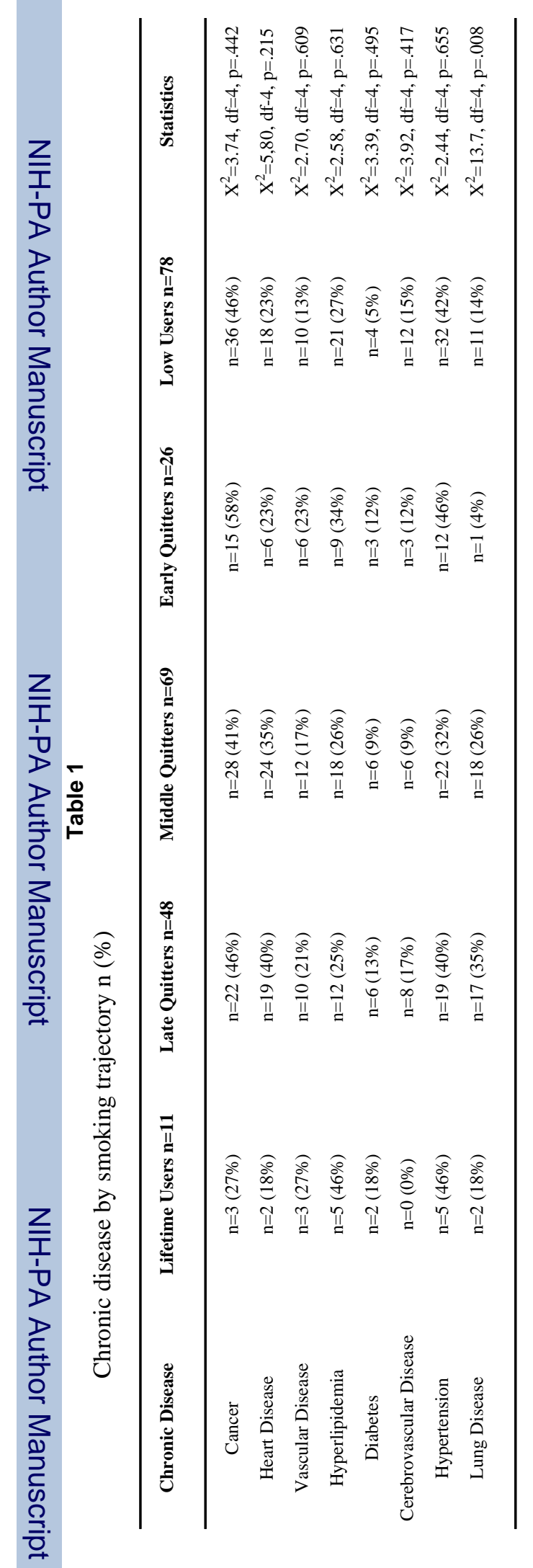

